harmful isoantibodies, causing haemolytic disease. ${ }^{8}$ Secondly, they can also transmit pathogenic autoantibodies, causing temporary neonatal thyrotoxicosis, myasthenia gravis, hypoparathyroidism, or thrombocytopenia in some cases when the mother has these diseases. ${ }^{9}$

A more dangerous state of affairs arises when the baby's central lymphoid systems fail to mature, giving rise to the immunological deficiency syndromes. No fewer than 20 syndromes have been listed by Good, ${ }^{10}$ associated with immunological deficiencies which can occur either as congenital malformations or as acquired diseases. The antibody deficiency states appear clinically as repeated infections by many different organisms, including all the common pathogens and yeasts such as monilia and Pneumocystis carinii. The mildest form of antibody deficiency is the transient hypogammaglobulinaemia of infancy, in which the synthesis of immunoglobulins is merely delayed. This can lead to multiple infections from about 6 months to several years of age, which can be helped by treatment with gammaglobulin. In this context it is of interest that premature babies, perforce born with underdeveloped immune responses, thrive better when given injections of immunoglobulins.

The most severe form of arrested maturation of immunity is the Swiss type of antibody deficiency, ${ }^{11}$ in which the thymus and the bursa-equivalents are atrophic. The disease is inherited as an autosomal recessive characteristic, and none of the affected children have survived beyond $2 \frac{1}{2}$ years in spite of attempts at thymus grafts. These children are unable to reject homografts ; in one case $45 \%$ of the circulating lymphocytes were found to be maternal, and the male infant died with symptoms reminiscent of the runting seen in graftversus-host reactions. ${ }^{12}$ The best-known form of antibody deficiency is the Bruton-type. ${ }^{13}$ It occurs in boys, and the thymus is normal though synthesis of immunoglobulin may be severely defective. These children can lead a normal life when treated with regular injections of gammaglobulin sufficient to maintain their blood concentration at around $200 \mathrm{mg} . / 100 \mathrm{ml}$., a level below which infections tend to recur. A third type of immune defect is characterized by severe hypoplasia of the thymus-dependent lymphocytes but with normal

1 Janeway, C. A., Arch. Dis. Childh., 1966, 41, 358.

Peter ibid., 1966, 41, 366.

Peterson, R. D. A., Cooper, M. D., and Good, R. A., Progr. med Genet, 1965, 4,1 .

- Good, R. A., Gabrielsen, A. E., Peterson, R. D. A., Finstead, J., and Cooper, M. D., in The Thymus, Ciba Symposium, p. 181, 1966. London.

Cooper, M. D., Peterson, R. D. A., South, M. A., and Good, R. A., F. exp. Med., 1966, 123, 75.

- Gabrielsen, A. E., and Good, R. A., Ann. intern. Med., 1966, 65, 607

Brambell, F. W. R., Lancet, 1966, 2, 1087.

- Brambell, F. W. R., Lancet, 1966, 2, 1087.

- Bcott, J. S., Brit. med. 7., 196

1. Good, R. A., in The Thymus, Ciba Symposium, p. 470, 1966. London.

Cottier, $\mathbf{H}$, in The Thymus in Immunobiology, ed. R. A. Good and A. E. Gabrielsen, p. 747, 1964. New York.

12 Kadowaki, J.-I., Thompson, R. I., Zuelzer, W. W., Woolley, P. V., Brough, A. J., and Gruber, D., Lancet, 1965, 2, 1152.

is Bruton, O. C., Pediatrics, 1952,9, 722.

14 Schaller, J., Davis, S. D., Ching, Y.-C., Lagunoff, D., Williams, C. P. S., and Wedgwood, R. J., Lancet, 1966, 2, 825.

is Mongan, E. S., Kern, W. A., and Terry, R., Ann. intern. Med., 1966 Mongan, 54.

16 te Velde, K., Huber, J., and van der Slikke, L. B., ibid., 1966, 65 ,

17 Fudenberg, H. H., Arthr. \& Rheum., 1966, 9, 464.

18 Dameshek, W., in The Thymus, Ciba Symposium, p. 476, 1966. London.

Boder, E., and Sedgwick, R. P., Little Club Clinics develop. Med. 1963, No. 8, 110.

20 Bloom, D., f. Pediatr., 1966, 68, 103.

"Sawitsky, A., Bloom, D., and German, J., Ann. intern. Med., 1966, 65,487

de Grouchy, J., ibid., 1966, 65, 603. G. L., Cancer (Philad.), 1965, 18, 216.
C., Bayrd, E. D., and Pease, formation of intestinal plasma cells. ${ }^{14}$ The patients may have autoimmune symptoms, particularly Coombs-positive haemolytic anaemia and an imbalance in the production of the different immunoglobulin classes $\operatorname{IgG}, \operatorname{IgA}, \operatorname{IgM}$, and $\operatorname{IgD}$. Similar anomalies are known to occur in patients with thymic tumours. ${ }^{1516}$

One of the most important developments in the study of immunological deficiencies is the link with autoimmunity on the one hand and malignant lymphomas on the other. ${ }^{317} 18$ In ataxia telangiectasia, ${ }^{19}$ a developmental disorder with dysglobulinaemia and antibody deficiency, a proportion of patients die of malignant lymphomas. A related disease, Bloom's syndrome, ${ }^{20}$ is also associated with increased susceptibility to infection and malignancy. Immunoglobulin studies have not yet been reported, but a chromosomal anomaly characterized by breakages and rearrangements has been described $^{21}$ which links it to Fanconi's anaemia, ${ }^{22}$ in which disease there is a bone-marrow aplasia rather like that seen in association with thymic tumours. ${ }^{23}$ It is possible that some maldevelopment of the central lymphoid apparatus, possibly making the primitive thymic cells susceptible to viral attack, may account for the interrelations between thymic dysplasias and tumours, antibody deficiency states, autoimmunity, and malignant lymphomas.

\section{Prolonged Endotracheal Intubation}

The treatment of respiratory difficulty by prolonged endotracheal intubation was first described by Sir William Macewen in $1880 .^{1} \mathrm{He}$ used it to treat two patients with obstruction of the upper respiratory tract. Despite the obvious advantages of endotracheal intubation over tracheostomy in terms of the ease of its performance, it was long thought that the method needed to be applied with great caution because of the risk of severe or even permanent damage to the larynx. But there is now increasing evidence that in fact endotracheal tubes may be left in for days or even weeks without serious sequelae provided certain prerequisites are met. The special complications of tracheostomy, ${ }^{2}$ such as pulmonary infection, haemorrhage, persistent fistulae, and tracheal stenosis, may be avoided, but endotracheal intubation does carry a risk of damage to the larynx, presents difficulties in the use of suction catheters, and perhaps is more unpleasant than tracheostomy for the patient.

The extent, therefore, to which prolonged endotracheal intubation is a satisfactory alternative to tracheostomy depends on a careful assessment and comparison of the drawbacks of each. In studying the effect of prolonged intubation on the larynx J. P. Tonkin and G. A. Harrison ${ }^{3}$ found in a series of 166 patients that the incidence of severe laryngeal trauma was $4.2 \%$. Though the incidence is higher than in any other published large series, ${ }^{4}$ the severe changes were not followed by any major permanent damage to the larynx so long as the period of intubation lasted no longer than 48 hours. Consequently these authors concluded that at least

'Macewen, W., Brit. med. F., 1880, 2, 122.

2 McClelland, R. M. A., ibid., 1965, $2,567$.

Tonkin, J. P., and Harrison, G. A., Med. F. Aust., 1966, 2, 581.

- Bergström, J., Acta oto-laryng. (Stockh.), 1962, 54, Suppl. No. 173.

Rees, G. J., and Owen-Thomas, J. B., Brit. F. Anaesth., 1966, 38, 901. Taylor, T.' H., Nightingale, D. A., and Simpson, B. R., Brit. med. 7 ., $1966,2,451$.

'Allen, T. H., and Steven, I. M., Brit. F. Anaesth., 1965, 37, 566.

McDonald, I. H., and Stocks, J. G., ibid., 1965, 37, 161.

- Thomas, D. V., Fletcher, G., Sunshine, P., Schafer, I. A., and Klaus M. H., f. Amer. med. Ass., 1965, 193, 183. 
for 48 hours tracheal intubation is a justifiable alternative to tracheostomy.

Tonkin and Harrison also clarify the factors responsible for laryngeal damage after intubation. They suggest that the important ones are trauma to the mucous membrane during intubation, female sex of the patient, and the presence of pre-existing laryngeal oedema caused by overinfusion. Duration of intubation beyond 48 hours and nature of the material of which the tube or the lubricant is composed are factors whose influence is not yet clear. They are in the process of being studied prospectively.

Prolonged endotracheal intubation also appears to be particularly indicated for infants and small children, in whom tracheostomy is associated with a high incidence of complications. $^{2}$ For infants nasal tubes are mostly used, and are generally made of polyvinyl chloride. One in particular ${ }^{5}$ has a crosspiece for connexion to the ventilator or other apparatus. Nevertheless, subglottic stenosis has been reported $^{5-7}$ after prolonged nasal endotracheal intubation in infants and small children. This is a serious matter, because as well as endangering life by causing respiratory obstruction stenosis is difficult to treat surgically. In an attempt to reduce the risk of this particular complication it is suggested ${ }^{7}$ that the tube should be small and that it should be lubricated with $1 \%$ hydrocortisone ointment in order to minimize any local inflammatory response. ${ }^{\circ}$

Accumulating experience of prolonged endotracheal intubation suggests that it can be a satisfactory alternative to tracheostomy, particularly in two types of patient: those with respiratory difficulty which is not likely to last longer than 48 hours, and small children and infants even if a longer period of artificial ventilation is needed.

\section{Ulcerative Colitis and Cancer}

Ulcerative colitis is a diffuse ulcerative condition of unknown aetiology affecting the mucous membrane of part or the whole of the large bowel. In the early stages there is an acute inflammatory change in the mucosa, and the crypts of Lieberkühn are distended with pus cells, inflammatory exudate, and mucus. ${ }^{1}$ These " crypt abscesses" are typical of ulcerative colitis, and as the crypt walls disintegrate and the overlying mucosa undergoes necrosis areas of ulceration are produced, which extend to the submucosa. In the most fulminating cases the inflammation spreads through the muscle coat to the peritoneal surface, and the bowel may undergo perforation. Usually the process remains superficial, and the destroyed mucosa and submucosa are replaced by granulation tissue, which when it matures to fibrous tissue causes shortening and stenosis of the bowel. During the phases of ulceration and healing portions of the mucous membrane are often elevated into polypoid excrescences. Some of these are merely ragged remnants of mucosa surviving amid extensive areas of ulceration. Others consist of a core of exuberant granulation tissue covered by a layer of epithelium. These mucosal projections are called pseudopolyps, because there is no increase in epithelial growth. They are not particularly prone to develop malignant change.

In the later stages of the disease the epithelium may undergo changes that culminate in cancer. True polypoid overgrowth of the mucosa is an early precancerous lesion, and it is sometimes seen scattered over much of the bowel. ${ }^{2}$ Probably between 3 and $5 \%$ of all cases of ulcerative colitis are complicated by carcinoma of the large bowel, ${ }^{3}$ while the risk of this complication is between five and ten times greater than in people without the disease. ${ }^{4}$ It is generally held that the prognosis of cancer in ulcerative colitis is worse than in sporadically occurring colonic cancer. ${ }^{5}$ The tumours are often multiple, and many of them are poorly differentiated or mucus secreting. ${ }^{6}$ Prophylactic proctocolectomy would certainly obviate the hazard of patients developing cancer, but it would lead to many patients who are not destined to develop cancer being subjected to a major operative procedure.

To define those groups of patients with ulcerative colitis who have a serious risk of developing carcinoma, J. M. Hinton has investigated a series of 32 patients with both lesions who were treated at St. Mark's Hospital in London. ${ }^{7}$ He found that when the colitis was confined to the rectum and sigmoid colon the risk of cancer was no greater than in the general population. When the disease affected the whole colon, on the other hand, the risk was greatest. Other important. factors were the duration of the colitis and the age of onset. Cancer was more likely to occur in those patients who were younger than 25 years when the colitis began, and it became an increasingly serious risk as the duration exceeded 10 years. Though the risk was very low for the first 10 years, it rose after this age-until by 25 years the cumulative risk was $42 \% .^{6}$ In Hinton's series of cases seven patients had more than one cancer present in the colon, and the transverse colon was affected much more frequently than it is in sporadically occurring carcinoma.

Other types of malignancy have also been reported as complications of ulcerative colitis. Primary lymphosarcoma of the large bowel-a rare condition-has been described in association with long-standing colitis on seven occasions. ${ }^{8}$ In another large series of cases of colitis a significantly increased incidence of carcinoma of the alimentary tract apart from the large bowel was found, and it was suggested that a widespread disturbance of the digestive system occurred in this disease. ${ }^{3}$ Another neoplasm that has been reported in association with ulcerative colitis is carcinoma of the bile ducts. J. G. Rankin and his colleagues have recently reported three cases of this uncommon tumour in a series of 441 patients with colitis. ${ }^{9}$ In every instance the colitis had been present for over 10 years before the carcinoma became clinically evident, and two of the patients died at the age of 22 years. Though pericholangitis is known to occur quite frequently in colitis, there was little to incriminate antecedent biliary disease in these three patients.

The relation between carcinoma of the bowel and ulcerative colitis still has many unexplained features. There appears to be no similar association between cancer and Crohn's disease of the large bowel-which suggests that the epithelial changes in colitis are of a different character. Despite the admirable epidemiological surveys designed to define the imminence of carcinoma, the lives of patients with ulcerative colitis will continue to be in jeopardy until precancerous lesions of the colon can be diagnosed with greater certainty.

\footnotetext{
Lumb, G., and Protheroe, R. H. B., Lancet, 1955, 2, 1208.

Dawson, I. P., and Pryse-Davies, J. Brit. F. Surg., 1959, 47, 113.

Edwards, F. C., and Truelove, S. C., Gut, 1964, 5, 1.

Goldgraber, M. B., and Kirsner, J. B., Cancer (Baltimore), 1964, 17 657.

Slaney, G., and Brooke, B. N., Lancet, 1959, 2, 694.

6 Morson, B. C., Gut, 1966, 7, 425.

Hinton, J. M., ibid., 1966, 7, 427.

Cornes, J. S., Smith, J. C., and Southwood, W. F. W., Brit. F. Surg., 1961, 49, 50.

- Rankin, J. G., Skyring, A. P., and Goulston, S. J. M., Gut, 1966, 7, 433 .
} 